\title{
Primitive Peritoneal Hydatic Calcified Cyst -A Case Report
}

\author{
Mountassir Moujahid', Issam En-nafaa' ${ }^{2}$ Issam Serghini' ${ }^{3}$, Karim Nadour¹, \\ Moulay Hassan Tahiri ${ }^{1}$ \\ ${ }^{1}$ Departement of General Surgery, $5^{\text {th }}$ Military Hospital, Guelmim, Morocco \\ ${ }^{2}$ Departement of Radiology, $5^{\text {th }}$ Military Hospital, Guelmim, Morocco \\ ${ }^{3}$ Departement of Reanimation, $5^{\text {th }}$ Military Hospital, Guelmim, Morocco \\ Email: $\underline{\text { m.moujahid@gmx.fr }}$
}

Received 11 February 2014; revised 10 March 2014; accepted 9 April 2014

Copyright (C) 2014 by authors and Scientific Research Publishing Inc.

This work is licensed under the Creative Commons Attribution International License (CC BY). http://creativecommons.org/licenses/by/4.0/

(c) (i) Open Access

\begin{abstract}
It is a cosmopolitan disease, due to the embryonic shape of taenia of the dog Ecchinococcosis granulosis. The peritoneal hydatidosis is the sowing of this serous in a primitive or secondary way. It can be caused by the massive break of a visceral hydatid cyst realizing the anaphylactic shock. Somewhere else, the discreet fissuring is the most usual realizing peritoneum cysts. So the peritoneal hydatidosis appears under polymorphic clinical painting according to the anatomical location of cysts. The disease puts a real problem of public health in our country. The primitive peritoneal localization is rare. We report a case of a primitive intra-peritoneal hydatid cyst.
\end{abstract}

\section{Keywords}

Hydatid Cyst, Calcified Cyst, Diagnostic and Treatment

\section{Introduction}

It is a cosmopolitan antropozoonosis, due to the embryonic shape of taenia of the dog, Ecchinococcosis granulosis, and bovine and ovine are the intermediate hosts. The man is an accidental host. The lung location is the second in frequency (15\% - 40\%) after the liver (40\% - 60\%) [1].

The peritoneal hydatidosis is the sowing of this serous in a primitive or secondary way. It can be caused by the massive break of a cyst visceral hydatid realizing the acute board of anaphylactic shock. Somewhere else, the discreet fissuring is the most usual realizing peritoneal cysts. So the peritoneal hydatidosis appears under polymorphic clinical symptom secondary to the anatomical localization of cysts.

It is the disease which raises a real problem of public health in our country. The peritoneal primitive localization is rare.

We report a case of intra-peritoneal hydatid primitive cyst.

How to cite this paper: Moujahid, M., En-nafaa, I., Serghini, I., Nadour, K. and Tahiri, M.H. (2014) Primitive Peritoneal Hydatic Calcified Cyst-A Case Report. International Journal of Clinical Medicine, 5, 440-443. 


\section{Observation}

45-year-old patient without notable pathological histories, admitted in the service for an abdominal pain died umbilical with a mobile and tangible abdominal mass evolving in a apyretic context and preservation of the general state; no notion of vomiting nor disorders of transit.

An abdominal echograph showed a measuring rounded formation $8 \mathrm{~cm}$ of main line evoking hydatid cyst of stage IV of the classification of Gharbi and Houssein requiring a complement CT scan.

The abdominal and pelvic scan showed a rounded formation $9,5 / 8 \mathrm{~cm}$, with calcified membrane in hails evoking a calcified hydatid cyst type $\mathrm{V}$, the liver, the spleen are without peculiarities as well as the bottom of bag of douglas. There is no intra peritoneal effusion (Figure 1).

The lung radiograph was normal, as well as the biological balance. The serology of the hydatic cyst was negative.

The patient is operated by a median laparotomy with realization of a cystectomy after liberation of the epiploic adhesions (Figure 2). The follow up were simple without any sign of second recurrence on a backward of two years.

\section{Discussion}

The hydatidosis is a cosmopolitan disease which rages in the endemic state in our country, it constitutes a real

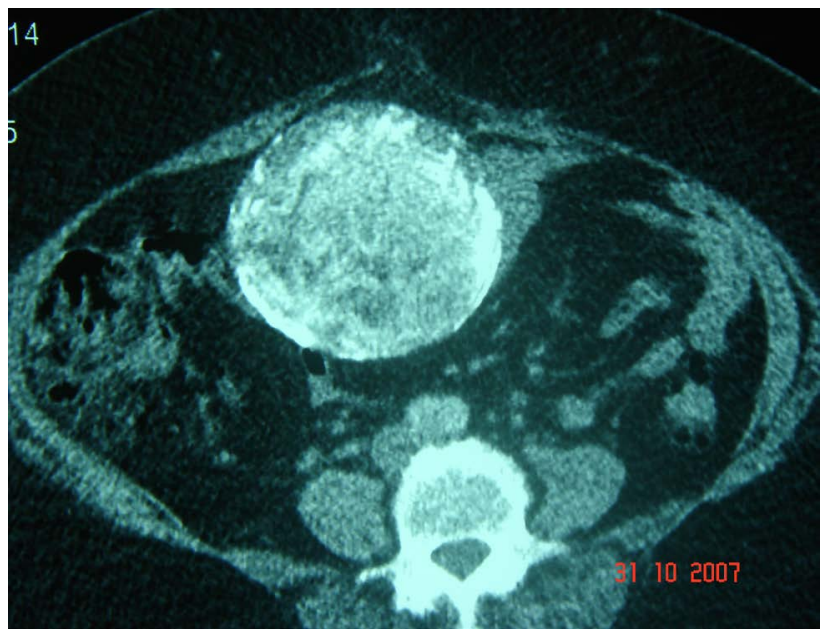

Figure 1. Abdominal scanner showing an intra peritoneal calcified cyst.

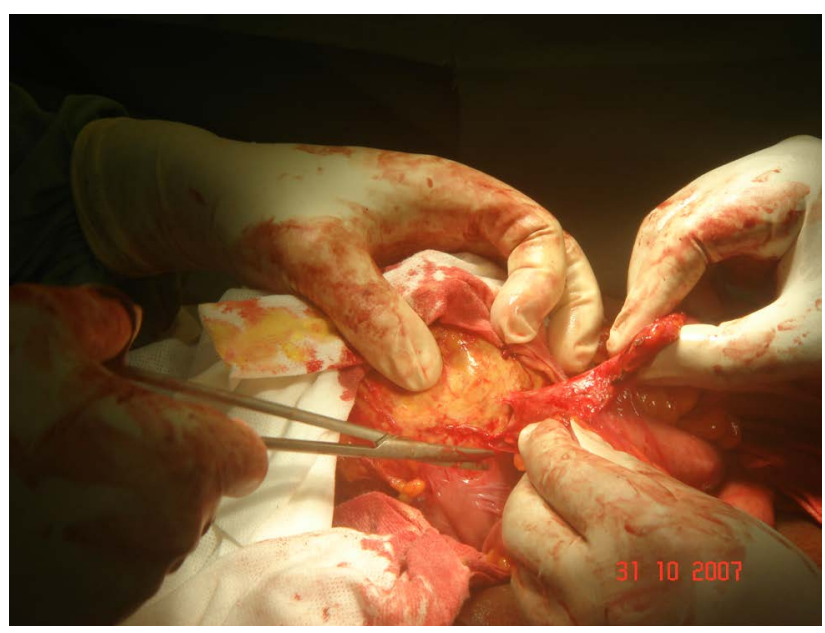

Figure 2. Operating view of this cystic formation with small intestine adhesions. 
problem of the public health.

Cysts can develop in all regions of the body with ascendancy for the liver and the lungs. The peritoneal hydatidosis is rare, its frequency varies from $0.30 \%$ to $4.27 \%$ of the hydatic localizations [1]. The primitive pelvic localization is exceptional, Bickers [2] counted 6 cases on 532 hydatic cysts. It can be primitive or secondary: the primitive shape is exceptional and is made either by hematogenic way or by heterotypic way by migration altogether of a hydatid cyst most of the time hepatic, having broken adventitious and kept it intact membrane [1] [3]. The secondary shape is often due to a fissuring or a break of a hepatic hydatid cyst, more exceptionally of spleen [2] [4], favored by a trauma sometimes junior and often underestimated. The highlighting of a peritoneal hydatid cyst in the absence of hydatic histories from a liver complaint or lung makes the diagnosis of primitive peritoneal hydatidosis.

The clinical symptom is variable secondary to the localization of the hydatid cyst, it can involve a pain with variable intensity and which can be accompanied by vomiting even a change of the general state. The interrogation looks for the notion of contact with dogs. Our patient has the notion of contact with dogs but presents no history of hydatic disease. The presence of an abdominal mass is frequent $99 \%$ by Moumen et al. [2], 40\% for Haddad et al. [4].

The serology of the hydatidosis has value only if it is positive.

The medical imaging plays an important role for the diagnosis of this affection. The echograph is the essential exam, its diagnostic reliability is considered at 96\% [1] [5] allowing to classify the hydatic cyst according to the classification of Gharbi and houssein in 4 stages [2] [3] [4] [6].

The scanning allows a more precise and easy diagnosis especially in the peritoneal localization [7].

The magnetic resonance imaging brings a diagnostic point in the case cysts are not characteristic in echograph or to scan [3] [7].

In imaging, the aspect reproduces the stages of the classification of Gharbi.

Type 1 has a pure cyst aspect: it is transonore in echograph, hypodense to scan and hyper intense T2 in MRI. The wall is thick.

The type 2 is more characteristic, with visible floating membranes in echograph and especially in MRI.

The type 3 is multi vesicular generally not raising diagnostic problem.

The type 4 is the more difficult diagnosis because of the heterogeneousnes of the lesion; the aspect is the one of a mixed, tissular mass and liquid contents, with parietal calcifications.

The type 5 corresponds to a more or less homogeneous, visible calcified mass on all the imaging techniques. The differential diagnosis of the peritoneal hydatid cyst arises with a cyst of the urachus, a not communicating digestive duplication. In this case the histological analysis of the wall that allows sitting the diagnosis, a mesenteric cyst, old underestimated and organized hematoma [1] [3] [8].

The peritoneal hydatid cyst can complicate pulling a hydatic peritonitis by break of the hydatic cyst in the peritoneum responsible for an anaphylactic shock, a secondary peritoneal hydatidosis, can be infect or be the origin of a compression of the organs of neighborhood [2] [4] [6].

The reference treatment is surgical [2] [6] [9] [10] associated sometimes with an anti-parasitic treatment by albendazole especially in case of a diffuse peritoneal hydatidosis.

\section{Conclusions}

The clinical symptom of the peritoneal hydatidosis is very polymorphic going of the simple fortuitous discovery to the generalized shape including some compressive forms.

The medical imaging is essential in the diagnosis, based on the echograph and the scanning.

The treatment is surgical coupled in some cases with the medical treatment with albendazole.

\section{References}

[1] Basaranoglu, M., Sonsuz, A., Perek, A., Perek, S. and Akin, P. (1998) Primary Pelvic Hydatid Cyst. Journal of Clinical Gastroenterology, 26, 157-158. http://dx.doi.org/10.1097/00004836-199803000-00018

[2] Moumen, M., El Alaoui, M.E., El Mansouri, A., et al. (1991) The Peritoneal Ecchinococcosis Problems DIagnostic and Therapeutic about 34 Cases. Chirurgie, 117, 845-849.

[3] El Mansari, O., Zentar, A., Sair, K., et al. (2000) Peritoneal Hydatidosis about Twelve Cases. Annales de Chirurgie, 125, 353-357. http://dx.doi.org/10.1016/S0003-3944(00)00206-6 
[4] Haddad, N., Tabbane, S. and Elouze, N. (1976) Clinical Aspects and Diagnostic Problems of Peritoneal Ecchinococcosis. Tunisie Médicale, 54, 735-764.

[5] Rosa, M. and Sahoo, S. (2009) Primary Hydatid Cyst of the Omentum. Diagnostic Cytopathology, 37, 117-118. http://dx.doi.org/10.1002/dc.20912

[6] Kehila, M., Allegue, M., Daoud, N., et al. (1985) Ultrasound and Surgical Correlation in the Abdominal Hydatid Cyst: About First 50 Cases Explored by Echograph in 1983-1984. Tunisie Médicale, 63, 545-548.

[7] Severino, A.D.M., Giancarrio, C.C., Franco, A.N., et al. (1990) Hydatid Disease: MR Imaging Study. Radiology, 175, 701-706.

[8] Prousalidis, J., Tzardinoglou, K., Sgouradis, L., et al. (1998) Uncommon Sites of Hydatid Disease. World Journal of Surgery, 22, 17-22. http://dx.doi.org/10.1007/s002689900343

[9] Mosca, F. (2004) Our Experience in the Surgical Treatment of Peritoneal Hydatid Disease. Giornale di Chirurgia, 25, 385-389.

[10] Nadeem, N., Khan, H., Fatimi, S., et al. (2006) Giant Multiple Intra-Abdominal Hydatid Cysts. Journal of Ayub Medical College Abbottabad, 18, 71-73. 